\title{
Historias de familia, historias de propiedad: dinámicas de parentesco en torno $a$ un antiguo latifundio del Nordeste de Brasil
}

\section{Fernanda Figurelli}

- Consejo Nacional de Investigaciones Científicas y Técnicas (CONICET)

Universidad Nacional de Misiones (UNaM) | Posadas, Argentina

$\boldsymbol{\nabla}$ ferfigus@yahoo.com.ar

\section{RESUMEN}

El artículo se basa en un trabajo de campo realizado en una región antes ocupada por una gran propiedad ganadera y algodonera de Rio Grande do Norte, Brasil. Archivos públicos y antiguos dueños y empleados transmiten una historia sobre la propiedad en la cual se destaca la familia que poseía ese patrimonio. Así, a la hora de pensar la propiedad son fundamentales los lazos de parentesco recreados por sus dueños. A su vez, la dinámica de esos lazos gira en torno a la concentración de las tierras. De este modo, más que entidades delimitadas a priori, observamos una relación mutuamente constitutiva entre familia y propiedad que cuestiona los límites entre "esfera pública" y "esfera privada". El artículo da cuenta de la familia como un proceso de producción permanente y procura mostrar las formas específicas que toma ese proceso, en el cual parentesco y concentración de tierras se muestran indisolubles. 


\section{UNA HISTORIA DE FAMILIA}

Por sesenta contos de réis João Pedro Melo, el "finado Juca", adquiere el dominio útil de "Belém".' Su hermano Miguel José Melo, la esposa e hijos de su hermano, y otros miembros de la familia: Paulo José Melo, José C. Carvalho y su esposa D. Anna Severina Melo transmiten el dominio de la propiedad por medio de una carta de adjudicación que se registra en el Libro 3 del Primer Cartório de Bom Jesus el 19 de octubre de 1920. ${ }^{2}$

"Belém" era una gran propiedad rural (una fazenda) localizada al sur de la región agreste de Rio Crande do Norte, Brasil, en la cual se criaba ganado y se producía algodón. Además del dueño y de su familia, se encontraba habitada por quienes se desempeñaban como su fuerza de trabajo, los moradores. Ellos vivían allí con sus familias y recibían una casa, la que suponía también tierra para hacer su propio rozado (roçado), en el cual plantaban productos destinados a la subsistencia familiar y, en menor cantidad, criaban animales para el autoconsumo. En contrapartida, todas las semanas debían dar al propietario un día de trabajo gratis (la diaria) y anualmente debían pagar un foro, definido por los ex moradores como un arrendamiento. También plantaban algodón, que era el cultivo comercial y que obligatoriamente debía ser vendido, en condiciones desfavorables, al dueño. Asimismo, en la propiedad existían trabajos que posicionaban en una más alta jerarquía a quienes los desempeñaban, entre estos el de vaquero, el cual se ligaba al patrón por un mecanismo diferente al del resto de los moradores. ${ }^{3}$

Actualmente, una parte importante de las tierras que conformaban Belém se encuentran divididas en varias comunidades habitadas por ex moradores que compraron allí pequeñas porciones de tierra. Un fragmento de ella es también hoy un asentamiento (assentamento) de reforma agraria, que resultó de una ocupación organizada por el sindicato de trabajadores rurales de Bom Jesus, ciudad referente de la región donde Belém se extendía. En este artículo me baso en una investigación realizada en aquella región y hago foco en los abordajes que algunos/as habitantes y ex habitantes del lugar, particularmente de la ciudad de Bom Jesus, hacen de Belém. ${ }^{4}$

“¿Por qué Belém?”, “¿tienes algún pariente de la fazenda?”: a lo largo de mi trabajo de campo, las alusiones a la familia propietaria (la familia Melo) fueron centrales. ${ }^{5}$ De manera frecuente escuché esas preguntas al conversar respecto al latifundio nordestino con personas que vivían en la ciudad de Bom Jesus, sobre todo con los/as funcionarios/as de las instituciones citadinas. Los intentos de esas personas por localizarme y localizar mi interés por "Belém" se constituyeron en un dato importante a la hora de visualizar los significados que la propiedad adquiría en sus perspectivas: ¿quién más adecuado que alguien de la familia
1 Un conto de réis equivale a un millón de réis. En 1942, el padrón monetario de Brasil réis fue reemplazado por el cruzeiro.

2 En este artículo, todos los nombres de personas y la mayoría de los nombres de lugares han sido cambiados.

3 Tal como Johnson (1971) observa en la propiedad rural de Ceará, en el caso de Belém el vaquero no debía ningún tipo de contribución al propietario. Cuidaba del ganado de este último y recibía sorte (un becerro de cada cuatro que nacían) como forma de pago, lo que le daba la posibilidad de tener su propio ganado. Tanto el vaquero como quien administraba los almacenes del propietario y otros trabajadores versados en determinada especialidad (carpinteros, herreros, etc.) también tenían una casa en la propiedad y ejercían la actividad agrícola, si bien ocupaban una posición diferente y de mayor jerarquía en esta estructura. Otra figura central es el administrador del propietario, quien se encargaba de supervisar a los moradores. En Belém se mencionan un administrador central y otros capangas que se distribuían a lo largo de la propiedad. Para fazendas de ganado en el Nordeste de Brasil, ver Cascudo (1956), Johnson (1971), Bastos (s/d), Almeida y Esterci (1977a, 1977b). Para un análisis del sistema de morada en sistemas de plantation cañera ver Sigaud (1971, 1979), Palmeira (1977), Heredia (1986).

4 Para otros abordajes de Belém ver Figurelli (2011).

5 Las traducciones de las conversaciones en el campo fueron realizadas por la autora. 
para interesarse por la "historia de la familia"? Así, entre fotos de familia, registros notariales y testamentos pasé a investigar una "historia de Belém"-como mis interlocutores/as se referían al asunto- que en este contexto remitía a la familia Melo y su patrimonio territorial. Familia y propiedad se entremezclaron, una familia poderosa ganó protagonismo en las conversaciones sobre el latifundio y me vi en la tarea de ir tras ella.

Cuando se habla de familias destacadas en el mundo "público" de la política o la economía, no es poco común preguntarnos sobre ese destaque, sobre cómo la familia en cuestión se apropia de la fortuna o el status o cómo acapara puestos políticos y administrativos. Probablemente, la pregunta se acompañe de alguna condena moral a tal infiltración o de rápidas asociaciones a resquicios del pasado, a formas de poder "tradicional" (y "local") sobreviviendo a "formas modernas"; estas últimas delimitadas, profesionalizadas y libres de aspectos impuros, como proclaman algunos modelos normativos de análisis político o algunas comparaciones antropológicas entre sociedades con y sin Estado.

El problema de ese modo de cuestionar es que, al indagar cómo las familias llegan o "se infiltran" en el dominio público, presupone a la familia como una entidad definida, constituida en torno a alguna esencia dada de antemano que la identifica, sea un conjunto de lazos -consanguíneos o de afinidad-, sea un apellido, sea una unidad de residencia, o el criterio que se seleccione. Esta reificación supone a su vez dominios separados: la familia y el poder, la familia y la política, la familia y la economía, donde la familia, confinada a lo "privado", se separa del mundo "público", en el cual se despliegan las formas "modernas" de la política y la administración.

En este artículo aporto herramientas para escapar de esa visión reificada de la familia, así como de su asociación automática a la esfera privada, e intentar pensar no cómo las familias a priori llegan a un poder público a priori, sino cómo las familias se arman en función de ese poder y como una y otro se encuentran interligados en su constitución. La "infiltración” en el mundo "público" es así mirada como constitutiva y no como un mero residuo del pasado no moderno o de "localismos" anacrónicos.

El camino ya fue abierto por diversos trabajos que han mostrado que las familias no son una entidad fija y que tampoco pertenecen a un mundo de "lo privado". Podemos extraer algunas pistas de autores como Pereira de Queiroz (1976), quien muestra un panorama dinámico de los "grupos de parentela" y destaca sus constantes procesos de constitución y fragmentación que entrelazan aspectos políticos, económicos y de parentesco. Canêdo (1998) observa cómo la construcción de un grupo familiar de Minas Gerais (particularmente a través de los casamientos) obedece a estrategias de ocupación de cargos públicos. Por otra parte, la conformación de redes sociales a partir de la circulación de niños 
entre diversos grupos domésticos, en barrios periféricos de Porto Alegre (Fonseca, 2002), también nos habla de familias dinámicas donde los criterios sociales de reciprocidad se vuelven constitutivos de esas dinámicas.

Entre investigadores ligados al Núcleo de Antropología de la Política (NuAP), el cual tiene su sede en el Museu Nacional de la Universidade Federal do Rio de Janeiro, estas cuestiones han sido trabajadas de manera explícita y sistemática. Al destacar las articulaciones entre familia y política, Palmeira y Barreira (2006) introducen trabajos que permiten pensar la redefinición permanente de lo que es interno o externo a la familia, cuestionando tanto la separación establecida de dominios como los límites a priori que los análisis de familias suelen dar a estas últimas. Así, el proceso narrado por Barreira (2006) muestra que los conflictos familiares y las redefiniciones de los límites familiares son constitutivos de las disputas electorales de los años 1998 y 2000 en el municipio estudiado. La autora describe cómo los sentimientos familiares se activan en las campañas electorales, lo cual resulta en una confusión de fronteras entre lo público y lo privado. Esas fronteras también quedan cuestionadas en el análisis de Neiburg (2006), quien al abordar de modo "total" una serie de eventos relacionados con la muerte de un miembro central de una familia poderosa de Argentina, hecho que coincide con la época de la presidencia de Perón, muestra cómo los conflictos y las reconfiguraciones familiares van de la mano de disputas políticas nacionales, siendo muy artificioso, abordado desde la vivencia de los participantes, separar ambas cuestiones. Intimidad y esfera pública se infiltran una en otra, lo familiar y local siendo asunto de política nacional, que se vuelve parte, esta última, del conflicto familiar. Por su parte, al analizar las luchas de familias en el sertão de Pernambuco, Marques (2002) muestra un panorama en el que las familias están lejos de designar estados fijos; por el contrario, las mismas se constituyen permanentemente y esa es una constitución pública que impregna y es impregnada por diversos planos vinculados a la política, al prestigio, a las relaciones de amistad, de compadrazgo y de vecindad, etc. De modo que la constitución misma de la familia es parte del mundo público. Otro tanto hace en este sentido el trabajo sobre sindicalismo rural de Comerford (2003), quien da cuenta de los límites imprecisos y flexibles de las familias, las cuales más que a una entidad aluden a procesos permanentes de composición y descomposición que se rigen en función de un público y en los que se construyen reputaciones.

Por su parte, en el giro que los estudios antropológicos del parentesco (o del pos-parentesco) han dado desde hace algunas décadas, encontramos dos discusiones que aquí nos resultan de particular interés. Una de ellas es el cuestionamiento a la búsqueda de estabilidad que ha caracterizado a los abordajes del parentesco. Contrariamente a eso, nuevos trabajos han puesto en primer plano la idea de un "proceso", en el cual el parentesco no es fijo, no está bioló- 
gicamente dado, ni es una construcción cultural sobre hechos de la naturaleza (que, como señala Strathern, no son ningún hecho), sino que es visto como una experiencia de "relacionalidad" (relatedness) que se construye cotidianamente (Carsten, 2000). El otro punto relevante para este trabajo es aquel que cuestiona la separación entre lo doméstico y lo político que ha marcado varios estudios antropológicos del parentesco (Yanagisako, 1979; Carsten, 2000; Weber, 2006).

En base a esos aportes, en este artículo muestro cómo, por un lado, lo que mis interlocutores Ilaman familia es una constante construcción que más que una estabilidad muestra una dinámica y cómo, por otro lado, esa construcción se encuentra entrelazada con "lo público", en este caso con la propiedad latifundista. La familia se constituye junto con esa propiedad. Su creación permanente se vuelve un asunto de orden "público" que no se desvincula de la distribución social de la tierra.

\section{LOS CONTADORES DE LA HISTORIA}

La narrativa sobre la familia destacó en un circuito "urbano" de investigación. Belém tenía una presencia en la ciudad de Bom Jesus y a medida que fui recorriendo algunas instituciones de esa ciudad la "historia de la familia" se hizo visible. Comentarios informales de personas con las que me topaba, entrevistas hechas con quienes fueron recomendados por tales personas y documentos disponibles en los archivos daban vida a esa historia.

Las recomendaciones de búsqueda en torno a "Belém" hechas principalmente por funcionarios y funcionarias de clase media de esa ciudad me llevaban a transitar un camino de investigación que se contorneaba entre las instituciones de la ciudad -y los documentos que en ellas se albergaban-y la familia propietaria. Principalmente, las sugerencias recaían en los herederos, los miembros todavía vivos de dicha familia que tejían o habían tejido relaciones en el lugar. Fueron algunos de los funcionarios que me brindaron los contactos de estos últimos. Las voces de esos miembros de la familia tienen un lugar central en la delimitación de la historia que aquí contaré. Además se incorporan otras voces, semejantes o diferentes de las de los herederos, pero coherentes con su abordaje de Belém, las cuales fueron contempladas por lo general a partir de una misma red de sugerencias. Así, podemos mencionar a funcionarios/as y documentos de instituciones como la escribanía (cartório), el Juzgado Civil (Vara Cível) o la Casa de Cultura Popular de Bom Jesus.

Por otra parte, también los viejos empleados de la propiedad ayudan a trazar la línea de puntos que permite demarcar esta historia. Entre ellos encontramos un trabajador del almacén de Belém y dos antiguos vaqueros, lo cual no pasa desapercibido si consideramos el estatus diferencial de los vaqueros en compara- 
ción con los demás trabajadores (Johnson, 1971) y la cercanía, tejida desde épocas antiguas, entre los dueños de esas grandes propiedades y los vaqueros, anteriormente esclavos (Cascudo, 1956). Fue un heredero el que me guió a Antônio, un antiguo vaquero de la propiedad, quien me hablaría sobre temas que dicho heredero no negaba como parte de la "historia de Belém", aunque los consideraba marginales a lo que él quería transmitirme. Los demás trabajadores, en cambio, no fueron recomendados en este circuito citadino de funcionarios y herederos. Así, al segundo vaquero, Manoel, llegué a partir de un dirigente del asentamiento mencionado en el apartado anterior, quien sugirió a aquel hombre viejo, antiguo vecino suyo, para que me contara "la historia de Belém". Mientras que Serafim, el antiguo empleado del almacén, fue recomendado por su nieta, una habitante de una comunidad situada en tierras que antes pertenecían a la propiedad, y por Manoel. Este último denominaba a Serafim como "el balancero" - ya que, entre otras funciones, pesaba el algodón que los moradores vendían.

De forma que las conversaciones con los propietarios (los llamados herederos), con algunos funcionarios y funcionarias de Bom Jesus, los datos de la escribanía, del Juzgado Civil y también un fragmento de las entrevistas a viejos empleados de la propiedad, se reúnen aquí para contar una historia polifónica, compuesta de trechos heterogéneos pero compatibles, de énfasis jerarquizados pero no contradictorios.

\section{“el CASAMiento NO eS BUENO Y DESMANTELA TODO"}

"Belém era una gran propiedady hoy los herederos no tienen nada de ese territorio": diversas personas de la ciudad me respondieron con esa frase cuando les decía que estaba investigando sobre Belém. La escuché de Eduardo y Claucia de la escribanía de Bom Jesus, de Alícia de la Casa de Cultura, de Edson de la Secretaría de Saúde, de Eva de la escribanía de Uruá (municipio vecino a Bom Jesus), y fue su repetición lo que me hizo percibir que allí estaba en juego una mirada sobre Belém que daba lugar a una historia definida. Es la historia de la familiay su patrimonio, la familia de mucho dinero y poder que experimentó un proceso de decadencia cuando Belém, uno de los más grandes e importantes latifundios de la región, fue disolviéndose entre varios dueños, de los cuales casi ninguno es un heredero de la familia. Es la historia que aquí presentaré.

La gran extensión es una característica remarcada de aquel patrimonio. Las personas cuentan que Belém abarcaba un considerable territorio conformado por los actuales municipios de Bom Jesus, São Sebastião, Serras, São Francisco, Aparecida, Bacia y Salvador. En general, se dice que la propiedad limitaba con algunos de estos municipios y se extendía sobre otros, siendo Bom Jesus el más importante entre los últimos. 
"Primero tienes que saber la procedencia de Belém, dónde fue creada Belém", me dijo Josias Melo, uno de los herederos de Belém que ya no posee aquel territorio. El origen eclesiástico de las tierras es de forma general el primer tema con el que las personas comienzan la historia. Las tierras eran de una santa llamada Nossa Senhora de Belém. ${ }^{6}$ Según lo señalado por datos del Primer Cartório de Bom Jesus aquellas tierras habían sido donadas a la Iglesia desde "tiempos inmemoriales". La mayoría de las versiones nos dice que los Melo las adquirieron por cesión del obispo de Gaivota, en Pernambuco, quien administraba aquel territorio de la Iglesia católica. ${ }^{7}$ Un miembro de la familia pidió al obispo la cesión. De acuerdo con Serafim, el "balancero", quien vivió en Belém desde 1919, el obispo de Pernambuco arrendó la propiedad para tres vidas: padre, hijo y nieto. ${ }^{8}$ De ese modo, los Melo adquirieron el dominio de la propiedad y como contrapartida de aquello comenzaron a pagar un diezmo a la Iglesia. Maria Lúcia, la dueña del Primer Cartório de Bom Jesus, me remitió al Primer Cartório de Uruá para localizar allí el registro anterior de Belém que data del dos de diciembre de 1817 y en el que figura como propietaria la Paróquia Imaculada Conceicão de Bom Jesus. Si bien en la escribanía de Uruá no pudieron localizar aquel registro, su sola citación ya nos brinda un dato sobre la propiedad de las tierras.

Poco a poco la presencia de la Iglesia se disipa en los relatos y comenzamos a entrar en terreno familiar. Luego de la cesión de Belém por parte de dicha institución, las adquisiciones de las que nos hablan las personas y los registros de la escribanía se efectúan principalmente dentro de la familia.

Las disputas entre los Melo no se hacen esperar y desde aquí comienzan a perfilarse los protagonistas de esta historia de Belém. Uno de ellos, ya citado al comienzo del artículo, es João Pedro Melo, conocido como el "finado Juca" entre los moradores, los empleados de la propiedad y a veces también entre los herederos (de quienes ]uca fue el padre de su padre de crianza). Tanto Josias como Serafim mencionaron que Juca había venido de Pernambuco. "En aquel tiempo era gente pobre, no tenían nada allá, eran todos pobres, entonces pagaron los derechos al obispo y fueron trabajando", mencionó Serafim. João Pedro Melo se convirtió luego en el único dueño de Belém. Aquello fue mediante un remate que, de acuerdo con Alícia, una funcionaria de Bom Jesus, se produjo a partir de la muerte del miembro de la familia que tenía a su cargo el dominio de la propiedad cedida por la Iglesia. ${ }^{9}$ El dominio debió repartirse entre los hermanos y por falta de acuerdo entre ellos terminó en un remate. ${ }^{10}$ "El remate no fue muy correcto" y generó resentimientos dentro de la familia, señaló Alícia. Miguel, el hermano de Juca, fue uno de los perjudicados. Manoel, antiguo vaquero de la propiedad, describió el evento: "Miguel puso cincuenta millones, entonces el otro dijo "no", Juca dijo "no" y puso sesenta millones en el remate, después no hubo nadie más que hablara. El viejo Juca remató".
6 A grandes rasgos, las tierras de santo se constituyen a partir de extensos territorios pertenecientes a la Iglesia que fueron por ésta abandonados, entregados o cedidos para ser utilizados en contrapartida de una renta o foro (los cuales suelen operar como contribución simbólica) (Almeida, 1993; Meyer, 1979). Como muestra Meyer (1979), más allá de su reconocimiento jurídico, el reconocimiento de la propiedad del santo por parte de los pobladores es un punto central a la hora de pensar este concepto.

7 Desde 1676 hasta 1892 la Diócesis de Olinda (Pernambuco) fue la sede eclesiástica del territorio que después se convirtió en Rio Grande do Norte. La Feligresía de Bom Jesus, creada en 1868, dependía de aquella administración. Sólo en 1910, un año después de la separación de Rio Grande do Norte de Paraíba, se creó la Diócesis de Natal que le otorgó al Estado autonomía eclesiástica (Cascudo, 1956 y Lyra, 1998 cit. en Azevedo, 2005).

8 Serafim trabajó en el almacén durante varios años para Tozé Melo, uno de los más importantes propietarios de la propiedad. Cuando este propietario murió, Serafim continuó realizando el mismo trabajo para Márcio Araújo, el esposo de una de las herederas de Tozé.

9 Alícia es la directora de la Casa de Cultura de Bom Jesus, cuyo bisabuelo se vio afectado por el remate.

10 Para relaciones entre hermanos en función de la propiedad heredada ver Segalen (1984). Por otro 
Hubo un desacuerdo entre los dos hermanos, Miguel y Juca. El desacuerdo fue avanzando y terminó en un remate, Belém fue rematada [...] El doctor Thiago Almeida, que era un abogado, dijo: -"Juca, Belém va a ser rematada y tú vas a comprarla" [...] Él []uca] dijo - "Pero yo no tengo dinero, doctor Thiago". - "Pero yo voy adquirir Belém para ti. Entonces entró en remate y la adquirió y el finado Juca le fue pagando después [...] Miguel perdió la pelea. Entonces el tío Miguel, con rabia, nunca entregó los papeles de Belém. Belém fue delimitada así, a ojo, por lo que puedo decir ¿sabes? Pero no fue legalizada [...] Miguel murió y no entregó los papeles. A hí listo, el finado Juca se hizo cargo. El doctor Thiago Almeida era el padre del doctor (Caio) Almeida, que fue juez acán"(Josias Melo).

Así, Belém pasó a manos de "un sólo dueño", el finado Juca, que luego fue sustituido por su hijo Antônio José Melo, más conocido como "Tozé Melo". Como señala Marques (2002), las peleas de familia no sólo desagregan, sino también son constitutivas de grupos; en este caso, las peleas entre hermanos desataron una concentración territorial que favoreció, al mismo tiempo, una concentración de los Melo. "El viejo Juca remató y pasó para el finado Tozé", prosiguió el antiguo vaquero. Por su parte, Josias y Antônio Melo Neto (Toninho), los herederos aún vivos de Belém (los ex propietarios de la tercera generación), señalaron que cuando el padre de Tozé murió, éste último debió comprar la parte de sus hermanos, quienes vivían en diferentes rincones de la propiedad. Juca "dejó un hijo en cada rincón (...) los desparramó por la propiedad, que era grande, para tener información de cómo estaba la propiedad, ¿entiendes?", me dijo Antônio Melo Neto. Tozé vivía a la orilla del río con su padre Juca, donde se encontraba la sede de la estancia. Cuando se casó se mudó a Taipal, sobre el camino de Bom Jesus a Serras, próximo a la primera ciudad, lugar que más tarde se transformó en la nueva sede.

Fernanda Figurelli: ¿Y quiénes eran los hermanos de Tozé?

Antônio Melo: Eran: ]oão Pedro Melo Filho [silencio], ¿quieres anotar?

FF: Está grabando [señalo el aparato].

AM: João Pedro Melo, Osvaldo Melo, que es Vado Melo, Josefa Melo que era la esposa de don Josué, y la mujer de Zé Medina era Francisca Melo Medina, ¿no?

Hermanos, hermanas y maridos de las hermanas, no hay mención a las esposas de los hermanos. El finado Juca murió en octubre de 1926 y entre 1928 y 1948 se registran en los libros de la escribanía varias adquisiciones del inmueble denominado "Belém" efectuadas por Antônio José Melo. Además de la herencia de una parte del territorio que recibe de su padre y de varias compras a miembros lado, es posible ver cómo los desacuerdos familiares (en torno a la propiedad) pasan aquí a formar parte de un plano administrativo, lo cual recuerda el análisis de Barreira (2006) sobre la expresión de conflictos familiares en las disputas electorales de un municipio de Ceará y la confusión de los dominios público y privado.

11 Dentro de las citas, las palabras que se presentan entre paréntesis son aquellas que no me quedaron suficientemente claras en la transcripción de las entrevistas. Las que figuran entre corchetes son aclaraciones mías. 
de la familia Melo, se halla también un pago de diez contos de réis a Don João Rocha de Ferreira, "domiciliado en la ciudad de Conceição, Estado de Pernambuco, en calidad de administrador de los patrimonios de su diócesis". A través de este pago, Antônio José Melo adquiere la "escritura de línea de dominio directo" de las tres leguas cuadradas de Belém, propiedad "poseída por donación desde tiempos inmemoriales". La adquisición se registra el 10 de abril de 1937. Tal vez esa sea la operación que describió Antônio Melo Neto cuando contó que su abuelo compró las tierras de Belém por recomendación de Domingo Azevedo, dueño del Banco Azevedo de João Pessoa, amigo y posterior socio de Tozé Melo, a quien este último vendía ganado. A diferencia de los documentos de la escribanía, Antônio estima la propiedad en una dimensión de siete leguas cuadradas. Según él, Belém había sido una sesmaria. ${ }^{12}$

“Después que el finado ]uca muere, queda el finado Tozé. Él fue allá [a Pernambuco] y compró el dominio al obispo, de la propiedad [...] El obispo recibió sesenta millones, y listo, Belém quedó toda para la família Melo", explicó Serafim. Por su parte, el ex vaquero en Belém de Antônio Melo Neto, Antônio Mendes, cuyo padre había sido vaquero de Tozé Melo, mencionó:

En la época yo escuchaba decir, porque en ese tiempo era muy joven, yo preguntaba para mi papá: "eh, papá, ¿cómo es que don Tozé compró toda esa tierra?". Él decía: "no, él no compró esa tierra, él compró el dominio al obispo", porque Ilamaba "la tierra de Nossa Senhora de Belém", porque esa tierra antiguamente era de esa Nossa Senhora de Belém, era de la Iglesia, ¿no?

La compra al obispo indica que hasta la entrada en escena de Tozé Melo la Iglesia no dejó de tener el dominio formal de esas tierras. Tanto Serafim como Antônio Melo Neto señalaron que el finado Juca pagó siempre un diezmo a esa entidad. Como observamos en el registro de la escribanía citado anteriormente y en la siguiente cita de Serafim, mediante aquella compra Tozé adquirió la escritura de Belém: "la segunda generación fue la que compró, fue allá y compró el dominio al obispo y él dio la escritura".

Tozé era ahora el único dueño de Belém y sería la figura más recordada en esta historia. "Don Tozé es ese..., Antônio Melo Neto pronunciaba esas palabras mientras señalaba el retrato que tenía colgado en la sala de su casa. "Después te voy a mostrar los retratos”, me dijo. Según él, su abuelo fue a Gaivota a conversar con el obispo y éste se interesó en la venta porque el diezmo que recibía era "un asunto simbólico".

Sin embargo, para Serafim (y otros moradores de Belém), la propiedad de las tierras por parte de Tozé Melo no es completamente legítima ya que las tierras son de la santa y como tales no pueden ser vendidas nunca:
12 En base a Monteiro (2007), podemos señalar que de 1530 a 1822 el acceso a la tierra fue hecho a través del sistema sesmarial, en el cual la corona portuguesa donaba grandes extensiones de tierra (las sesmarias) que luego eran transmitidas por herencia. Durante el período colonial se daba también la ocupación de grandes áreas por parte de señores rurales, la cual se volvió, a partir de la Independencia y con la extinción del sistema sesmarial, la forma predominante de adquisición hasta 1850, cuando se decretó la Ley de Tierras (la misma determinaba que las tierras del Estado sólo podrían adquirirse por compra, además elevaba el precio de las mismas y disponía que las tierras ya adquiridas por donación y ocupación podrían ser legalizadas sólo si fueron explotadas). El sistema sesmarial permitió que toda la caatinga, tanto en el Agreste como en el Sertão, fuese apropiada, desde la época colonial, por grandes latifundios, cuya ocupación económica sólo ocurrió en épocas posteriores (Furtado, 1964). Según Andrade (1998), las sesmarias tuvieron en sus inicios dimensiones ilimitadas, en 1695 se estableció una extensión máxima de cuatro leguas por una, la cual se redujo a tres leguas por una en 1729 (lo que superaría las 10.000 ha.) y a una legua al cuadrado en el siglo XIX. En el caso que nos ocupa, es probable que Belém haya sido una sesmaria que luego fue donada a la Iglesia. 
la Iglesia y el obispo eran quienes resolvían todo, fueron los que vendieron el patrimonio de la santa a la familia Melo [...] El finado Tozé compró el dominio al obispo y quedó para él de una sola vez, pero no sé cómo, porque el patrimonio de la santa no puede ser vendido nunca, todo eso es patrimonio de una santa.

Tozé y su esposa, Maria Josefina Melo (quien según Alícia había sido una "moradora"), fueron padres de crianza (criação), y posteriormente también padres adoptivos, de sus sobrinos, de un nieto y del padre de este nieto, los hijos que en esta historia serían recordados no como "los dueños" sino como "los herederos", asociados a la decadencia de Belém. ${ }^{13}$

Josias: El hombre rico de acá era él, él no tenía familia, entonces un día iba pasando por allá, por la casa de mi padre legítimo, João Pedro Melo Filho, le decían João Melo, y vio un chiquitito así, mi hermano, un rubiecito así:

- "Voy a llevarme a ese chico para criarlo" [...] Entonces el chico dijo:

-"Yo solo voy siél va, si Josias va. Yo no voy solo, voy con él".

FF: ¿Y tu hermano cómo se llamaba?

J: Luis Duarte Melo. Entonces vinimos él [Luis] y yo. Pero él [Tozé] ya criaba también una hermana mía que se llamaba Eli, que ya murió, y criaba otro, que era el finado Zé Duarte, que era tío legítimo mío, era hermano de mi (mamá). Él me crió y crió a Luis, a Eli y al finado Zé Duarte, y a Toninho, que fue intendente acá, era nie to yél lo crió también, crió cinco personas el finado Tozé, porque él no tenía familia ¿sabes? No construyó familia de ningún modo, entonces crió toda esa gente.

Así surgía la tercera generación Melo de Belém. Tozé y Maria fueron construyendo el trazado genealógico de la familia a través de la crianza de algunos de sus parientes legítimos, así llamados por los entrevistados a los parentescos construidos a partir del nacimiento (ver figuras I y II). Si bien algunos de estos lazos legítimos de parentesco son aclarados por los herederos que entrevisté, en general sus relatos privilegian los lazos construidos por Tozé a través de la crianza, de manera que algunos datos referentes a los vínculos de parentesco legítimo quedan en la oscuridad. Tozé crió a Josias Duarte Melo, a Maria Duarte Melo (más conocida por Eli), a Luis Duarte Melo y a José Duarte Melo, ${ }^{14}$ quienes eran los hijos legítimos de su hermano legítimo: João Pedro Melo Filho. Además crió a José Duarte Melo (Zé Duarte), padre legítimo de Antônio Melo Neto, este último también criado por Tozé y más tarde por Eli. El parentesco de estos últimos con Tozé Melo, previo a la crianza, no fue suficientemente aclarado. Josias señaló que José Duarte Melo era un tío legítimo suyo, hermano de su madre de nacimiento. Por su parte, en el Proceso de Inventario de Antônio José Melo se describe a uno de los José Duarte Melo como "primo legítimo" de aquél y a Antônio Melo Neto como "primo de segundo grado".
13 Sobre "hijos de crianza" y circulación de niños ver el trabajo ya citado de Fonseca (2002).

14 Éste era llamado Zé Melo o José Duarte Melo Sobrinho, para distinguirlo de su tocayo (Zé Duarte), el padre legítimo de Antônio Melo Neto. A pesar que en varios momentos se señaló a Zé Melo como un "hijo de crianza" (filho de criação) de Tozé Melo, los relatos de los herederos también transparentaron cierta ambigüedad respecto de esa relación, ya que su edad era avanzada (17 018 años) al llegar a la crianza de Tozé. 


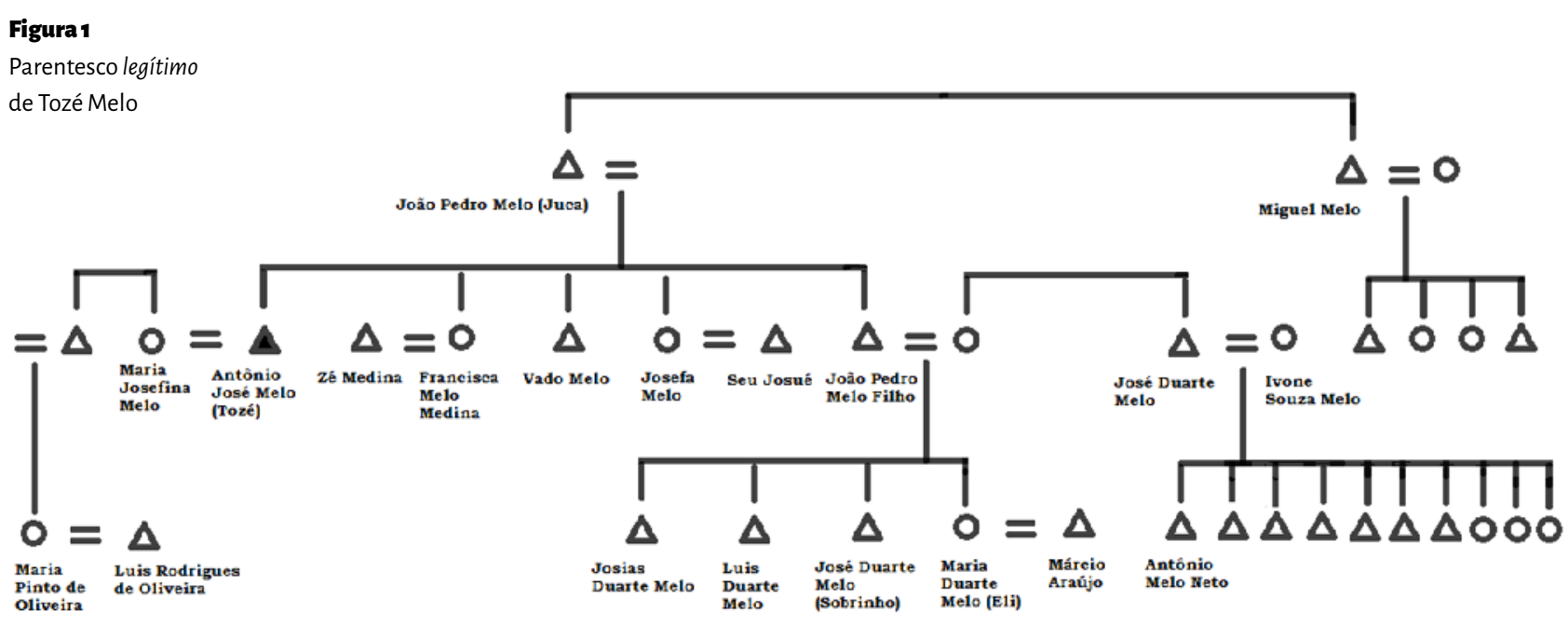

\section{Figura 2}

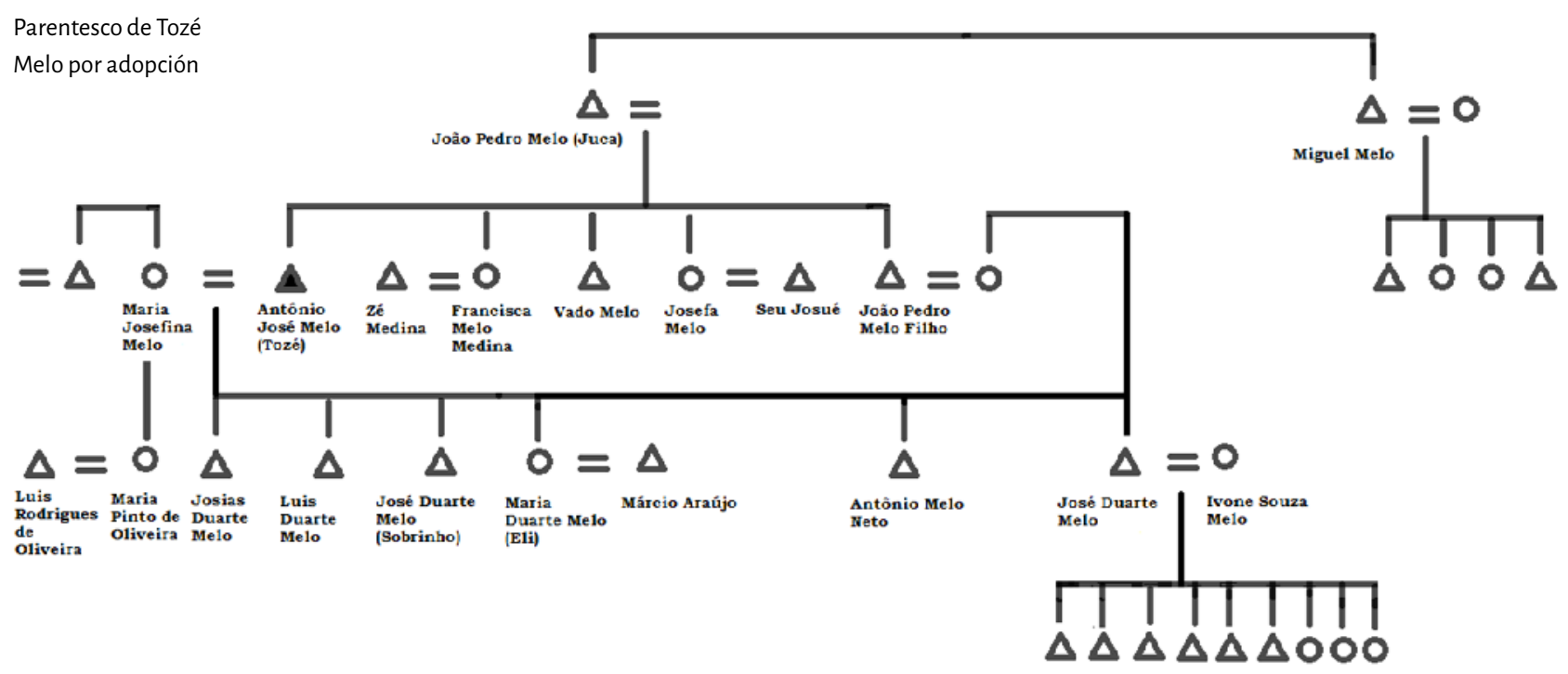

Serían los hijos de crianza (filhos de criação) de Tozé, además de su hermano, quienes recibirían su herencia. Según lo muestra el Proceso de Inventario, pocos meses antes de morir, Tozé Melo realizó una "escritura pública de adopción" de sus seis hijos de crianza (incluyendo a José Duarte Melo Sobrinho). Algunos días antes de aquello, forjó su testamento para la mitad de sus bienes.

En abril de 1957, Tozé murió en su casa en João Pessoa donde se encontraba realizando un tratamiento de salud. Su cuerpo fue trasladado hacia Bom Jesus, lugar en el que fue sepultado. En el Proceso de Inventario e Partilha de sus bienes, Belém fue calculada en una medida de 16.439,9080 metros cuadrados, y fue descripta como constituida de caatinga y gran parte de arisco (suelo arenoso), con aproximadamente cuatrocientas casas de taipa (de barro y madera) y cuatro de ladrillo, cultivada en un área de alrededor de mil hectá- 
reas. Maria Josefina Melo, viuda de Antônio José Melo, con quien éste era casado por el "régimen de comunidad de bienes", recibió la mitad de la propiedad, 8.219,9540 metros cuadrados y, de acuerdo a lo dispuesto en el testamento, lo restante fue subdividido en partes iguales entre sus seis herederos, sus hijos adoptivos (Josias Duarte Melo, Luis Duarte Melo, Maria Duarte Melo, José Duarte Melo, José Duarte Melo -Zé Duarte-y Antônio Melo Neto) y su legatario colateral (João Pedro Melo Filho). Según el Inventario, en aquella época, Josias (de 25 años), Maria (de 35 años), Luis (de 22 años), José Duarte Melo Sobrinho (de 31 años) y João Pedro residían todos en Belém. Por su parte, José Duarte Melo (Zé Duarte) (de 40 años) y Antônio Melo Neto (de 13) tenían su residencia en João Pessoa.

Además de la propiedad, se dividieron quinientas cabezas de ganado vacuno, diez caballos, un automóvil Ford modelo 1955, un Jeep Willys modelo 1951 en mal estado de conservación, una casa residencial en João Pessoa y depósitos bancarios. No viene al caso describir aquí la repartición exacta de estos bienes, que fue realizada en partes más o menos iguales, excluyendo lo recibido por la esposa, quien obtuvo el mayor reparto.

Casi dos años y medio más tarde, el siete de octubre de 1959, moriría Maria Josefina Melo y ocurriría una nueva división. De acuerdo con el Proceso de Inventario, los herederos serían los mismos que los de Tozé, a excepción de João Pedro Melo Filho y José Duarte Melo Sobrinho (lo que podría pensarse como otro dato respecto del carácter incierto de su crianza por parte de Tozé y Maria). Por otra parte, en relación con José Duarte Melo (Zé Duarte), no fue él sino sus hijos quienes recibieron el legado. Además, se sumaría Maria Pinto de Oliveira, quien era hija del hermano de Maria Josefina Melo e hija adoptiva de esta última. De modo que la mitad de Belém, medida en 8.220 hectáreas, donde se incluía la región denominada Taipal, en la que existía un embalse, la casa sede de la estancia, corrales, almacenes y otras construcciones, se distribuyó de la siguiente manera: 1500 hectáreas fueron dadas a Antônio Melo Neto; Maria Duarte Melo (en esa época ya casada con Márcio Araújo, pasando a firmar como Maria Melo de Araújo) obtuvo 2000 ha.; Josias Duarte Melo adquirió 1180 ha., al igual que Luis Duarte Melo y Maria Pinto de Oliveira (quien se casó con Luis Rodrigues de Oliveira, el chofer de Tozé, muy querido por este último según Antônio Melo Neto). Los nueve hijos del matrimonio de José Duarte Melo (Zé Duarte) e Ivone Souza Melo, cuyas edades ocupaban una gama que iba de los primeros meses a los 15 años, también obtuvieron 1180 ha. (a excepción de Antônio Melo Neto). Además de la mitad de Belém, Maria legó sus joyas, el automóvil Ford y 250 cabezas de ganado vacuno. Todo aquello fue cedido por testamento realizado en septiembre de 1958.

¿Y después cómo fue? Pregunté. 
Josias: Y a hí cada uno se quedó con su parte, las partes fueron divididas, entonces cada uno se hizo cargo de lo suyo. Pero hubo much familia desunida, si fuera una familia unida hoy todavía sería un patrimonio muy grande. Pero, tú sabes, ahí vinieron las desavenencias, las discordias, todas esas cosas, ¿sabes?

En palabras de Manoel, el vaquero, "ahí se acabó, el viejo Tozé murió y la partió todita para los sobrinos”. Los relatos localizan en la muerte de Tozé Melo el "comienzo del fin" de la gran Belém, el latifundio emprendía el descenso. Convertida en herencia a partir de esta muerte, la gran propiedad comenzaría a desagregarse y junto con su patrimonio también lo haría la familia. La primera en vender fue Maria Pinto de Oliveira, cuyas operaciones se destinaron a varios compradores. Desde entonces, los registros de Belém que se encuentran en los libros de la escribanía comienzan a ser numerosos.

Años atrás, no sé si fue en el 58... parece que fue en el 57... él falleció. Ahí fue dividida para los herederos y fue quedando pequeña, un pedazo para uno, otro pedazo para otro, había muchos herederos, entonces, la gente, unos fueron saliendo, otros de esos herederos fueron vendiendo. Y las personas fueron comprando, los que moraban. Fueron comprando, fueron comprando, y listo. Hoy de la familia que era dueña de ahí ya no hay casi nadie. (Antônio, el vaquero).

Con la venta de los herederos, la gran Belém acabó. No obstante, si volvemos a la última cita de Josias se evidencia que la división del patrimonio no se agota en la venta de tierras por parte de los herederos. La división refiere fundamentalmente a los vínculos "familiares", cuestión central en esta historia que los propietarios y las instituciones de la ciudad transmiten. "Cada uno se hizo cargo de su pedazo", volvió a decir Josias, "entonces se vendió, desunión y esas cosas, casamiento mal casado, tú sabes, el casamiento no es bueno y desmantela todo". El fin de Belém se entreteje con las relaciones entre y de los herederos de aquel patrimonio que no supieron mantenerlo unido. Josias no fue específico en su alusión a los casamientos, Belém se desagregó por "asunto mal hecho, pelea de familia, esas cosas, ¿sabes?”. Por su parte, cuando le pregunté a Alícia sobre el fin de Belém, ella me habló específicamente del casamiento de Eli, lo cual me sorprendió ya que los herederos fueron varios. Sin embargo, Eli era la única mujer entre los que habían recibido una herencia importante y su casamiento traería herederos de otro apellido o, podríamos decir aquí, de otra "familia" que, en perjuicio del patrimonio, era incompatible con el proceso de concentración que Tozé había emprendido:

Fue lo siguiente: Cuando Tozé murió [...] Eli va y se casa con una persona que ya 
era casada, ya tenía hijos, Márcio Araújo. Y ella se involucró. Porque ella estaba comprometida con un muchacho soltero, con un primo que la familia quería y todo. Yél [Márcio] vino para trabajar en la fazenda ya con mujer cargada de hijos, casado por iglesia. Entonces no sé bien cómo fue que ella entro en esa onda, de hombre casado, Ileno de hijos, que no tenía dónde caer muerto (...) Entonces él huye con ella y se casan. Entonces, cuando vienen, él dominaba, ¿no?, él estaba interesado en eso, el padre ya había muerto, porque (ella) hizo eso solo porque Antônio Melo ya había muerto. Enseguida, la madre muere, entoncesél se hace cargo (...) Entonces está la cuestión de los hijos de él que heredaron. (Alícia).

Con el casamiento de Eli, el trazado genealógico de los Melo llega a su fin. Canêdo (1998) observa la reconstrucción genealógica como una herramienta política que, desde un determinado interés, da identidad y continuidad a la familia que se reconstruye. En el caso de los Melo, es posible ver como dicha reconstrucción se realiza en función de la concentración del patrimonio, lo cual se quiebra a partir del casamiento señalado. Al hablar sobre la decadencia de Belém y el final de los Melo, también Manoel enfatizó el casamiento de Eli, quien no sólo era heredera mujer, sino también una figura central para la propiedad y su administración. “Después de Tozé quién vino", le pregunté:

Después de Tozé quedó su sobrina, la hija de João Melo que criaba, se llamaba Eli, era quien se hacía cargo de todo en esa fazenda, criada en casa, ¿no? Cuando el viejo Tozé murió, ella puso al empleado y el empleado se fue a vivir con ella, Márcio Araújo (...). Se casó con la hija de crianza del viejo Tozé y se quedó con toda la riqueza.

Ya sea porque Eli une Belém y los Melo a un apellido sin patrimonio (y que trae consigo herederos ajenos a la familia), ya sea por una desunión familiar (lo que puede leerse como una desunión entre los herederos, que compartían el apellido Melo) en la que "cada uno quedó con su pedazo", la historia de Belém experimenta una ruptura con la muerte de Tozé y en gran medida esta ruptura se asocia a los vínculos familiares. Con la muerte de Tozé el latifundio se dividió entre los herederos. Sin embargo, la verdadera división ocurre después, con la "desunión familiar" y los "casamientos mal casados": al fin y al cabo los herederos llevaban todos el apellido Melo. El patrimonio se dividía y los Melo junto con él. Mientras la familia se dividía el patrimonio se desagregaba, y esta ruptura ponía en evidencia la interpenetración de uno y otro. Belém significaba Melo, un propietario concentrado. Al mismo tiempo, la familia significaba un apellido y su patrimonio, un patrimonio concentrado. Ninguno de ellos puede mencionarse sin el otro, la idea de familia se entreteje con la de patrimonio. 
Es posible observar procesos de familiarización y desfamiliarización (Comerford, 2003) en los que "los Melo" se hacen y deshacen. "Entonces él dijo: 'voy llevando a los chicos', entonces él iba llevando a los chicos para criar, ¿entiendes?", me había dicho Antônio Melo Neto: asistimos, por un lado, al proceso de familiarización en el cual Tozé llevó a su casa a los hijos legítimos de su hermano y a sus primos legítimos para criarlos y convertirlos en los posteriores herederos de sus tierras. Mis interlocutores consideraron que sólo con herederos Tozé y su esposa tuvieron una familia. Antes vimos la familiarización a la cual contribuyeron, paradójicamente, las disputas familiares que crearon la grandeza de los Melo cuando el finado Juca se peleó con sus hermanosy pasó a ser el único dueño de Belém, un proceso donde la grandeza familiar se sustentó sobre las rupturas fraternales que posibilitaron la concentración del patrimonio.Por fin, este camino familiarizador se desanda hasta llegar al desenlace de Belém, a la desfamiliarización que ocurre con las "desuniones" entre hermanos de crianza y "casamientos errados" posteriores a la división formal del patrimonio. No hubo un nuevo movimiento familiarizador: las porciones se fueron vendiendo. Tampoco hubo una concentración del territorio: los Melo se fueron disolviendo en un entretejido de apellidos sin patrimonio.

Estos procesos permiten dar cuenta de una incesante fabricación de la "familia Melo" que es indisoluble de la construcción del poder del gran propietario. Observamos que la "familia" se construye en torno a las relaciones que contribuyen a la concentración del patrimonio. La familia Melo se hace y se deshace y los parámetros que dan significado a ese hacerse y deshacerse se encuentran ligados a la propiedad. Las relaciones que concentran el patrimonio familiarizan y, a la inversa, las relaciones que lo deshacen implican una disolución de la familia. El finado Juca rompe con sus hermanos y concentra el patrimonio que continúa con sus herederos. Por su parte, Tozé adquiere el patrimonio de sus hermanos y concentra la herencia de su padre. Sin embargo, sin herederos aquella concentración pierde su sentido, y también lo pierde la idea de familia. Para la construcción de su hegemonía precisa de los hijos que otorgarán sentido a la herencia, al poder de legar que este propietario adquirió. Es sólo incorporando hijos que Tozé tendrá una familia o, podemos decir, que Tozé consolidará su hegemonía. Es sólo con herederos que la noción de familia se hace presente.

Por otra parte, Belém comienza a ser narrada desde que los Melo adquieren el dominio y crean la propiedad. Hay menciones a las tierras de la santa, sin embargo, no se sabe mucho de ello, ni en los registros institucionales, ni en los relatos de las personas. Una nube de incertidumbre se extiende hacia "tiempos inmemoriales", cuando las tierras habían sido donadas a la iglesia (más exactamente, a la santa), antes que los Melo llegaran. La memoria de la familia, en cambio, disipa la nube y Belém se narra a partir de esa memoria. Lo que importa 
de la formación de Belém es la conjunción de las tierras con los propietarios, el surgimiento del patrimonio familiar.

\section{CONCLUSIONES}

Sería arbitrario relegar las dinámicas de parentesco descriptas a un plano separado de lo comúnmente considerado "público". Crianzas, casamientos, adopciones, lazos fraternos afectan y se ven afectados por formas sociales de apropiación territorial. Por otro lado, la historia de la familia es constitutiva de la historia del lugar y circula públicamente entre personas relacionadas entre sí por medio de lazos que superan los estrictamente familiares. ¿Cuáles relaciones corresponderían al ámbito "privado" y cuáles al ámbito "público"? En este abordaje no tiene sentido sostener la dicotomía, la separación analítica entorpecería la comprensión. Las dinámicas económicas, regionales y familiares integran un mismo proceso. La conformación de la familia es parte de un movimiento de mayor repercusión en el que se ponen en juego modos de concentración de tierras. Además, su historia alcanza una escala amplia y es incorporada y apropiada por un público que no interviene directamente en su constitución. La familia carga consigo, para usar las palabras de Neiburg (2006: 336), "una pluralidad de agentes y significados asociados con la publicidad".

Las narrativas que aquí consideramos nos muestran una construcción permanente de la familia en la que los vínculos se van configurando de forma acoplada a la propiedad y a la edificación del poder del propietario. La historia de la gran propiedad se muestra inseparable de la de la familia, los lazos de parentesco de quienes poseían Belém son parte de esa historia. A su vez, la familia nos remite a procesos de agregación y desagregación que se rigen en torno a la propiedady, de este modo, vemos una mutua y dinámica constitución. El patrimonio nos envía a relaciones entre personas, en este caso, a familiarizaciones y desfamiliarizaciones, que, al mismo tiempo, son inseparables de acciones de compra, venta, remate y herencia.

Las relaciones rescatadas en esta historia y el trazado del árbol genealógico de la familia Melo van de la mano con la historia del patrimonio. La propiedad de la tierra guía el proceso de parentesco. Más que una familia fija vemos una familia dinámica y esa dinámica se rige en torno a la concentración de la propiedad. De este modo, familia y distribución social de la tierra quedan entrelazadas. No se trata de entidades delimitadas a priori, una perteneciendo a la esfera de lo privado y la otra a la esfera pública. Por el contrario, la ocupación del territorio es parte constitutiva de una conformación familiar que, a su vez, constituye esos asuntos de dominio público. 
Fernanda Figurelli es investigadora del Consejo Nacional de Investigaciones Científicas y Técnicas (CONICET), Argentina. Doctora y Magíster en Antropología Social por el Programa de Pós-Craduação em Antropologia Social, Museu Nacional, UFR], y Licenciada en Antropología Social por la Universidad Nacional de Misiones, Argentina.

\section{REFERENCIAS BIBLIOCRÁFICAS}

ALMEIDA, Alfredo Wagner Berno de e ESTERCI, Neide

1977a "Quixadá: A formação do povoado e o aceso à terra pelos pequenos produtores". In Projeto Emprego e Mudança Sócio Econômica no Nordeste. Museu Nacional/UFR], Mimeo.

1977b "Terras soltas e o avanço das cercas". In Projeto Emprego e Mudança Sócio Econômica no Nordeste, Museu Nacional/UFR], Mimeo.

ALMEIDA, Alfredo Wagner Berno de

1993 "Tierras de Negro, Tierras de Santo, Tierras de Indio: Uso común y conflicto". Revista Con-textos. Después de la piel: 500 años de confusión entre desigualdad y diferencia. Posadas, Departamento de Antropología Social, FHyCS, UNaM, pp. 118-135.

ANDRADE, Manuel Correia de 1998 [1963] A terra e o homem no Nordeste: Contribuição ao estudo da questão agrária no Nordeste, $6^{\text {a }}$ Ed. Recife, Editora Universitária da UFPE.

AZEVEDO, Karla Isabella Brito de Souza

2005 Entre a anta e a cruz: História e memória da cidade de Nova Cruz-RN. Natal, dissertação, Universidade Federal do Rio Grande do Norte.

BARREIRA, Irlys

2006 "Campanhas em família: as veias abertas das disputas eleitorais". In PALMEIRA, Moacir e BARREIRA, Cesar (orgs.).Política no Brasil: visões de antropólogos. Rio de janeiro, Relume Dumará, Núcleo de Antropologia da Política/UFR], pp. 301-332.

BASTOS, Eliane Cantarino O'Dwyer Conçalves

s/d. A cultura de algodão no sertão paraibano, Mimeo. 
CANÊDO, Letícia Bicalho

1998 "La Production généalogique et les modes de transmission d'un capital politique familial dans le Minas Gerais brésilien". Genèses, Paris, 31: 4-28.

CARSTEN, Janet

2000 "Introduction: Cultures of Relatedness". In: Cultures of Relatedness: New Approaches to the Study of Kinship. United Kingdom, Cambridge University Press, pp. 1-36.

CASCUDO, Luís da Câmara

1956 Tradições populares da pecuária nordestina. Rio de Janeiro, Ministério da Agricultura, Serviço de Informação Agrícola.

COMERFORD, John

2003 Como uma família: Sociabilidade, territórios de parentesco e sindicalismo rural. Rio de Janeiro, Relume Dumará, Núcleo de Antropologia da Política/UFR].

FICURELLI, Mónica Fernanda

2011 Família, escravidão, luta: histórias contadas de uma antiga fazenda. Rio de Janeiro, tese, Universidade Federal do Rio de Janeiro.

FONSECA, Claudia

[1995] 2002 Caminhos da Adoção, $2^{\mathrm{a}}$ Ed. São Paulo, Cortez.

FURTADO, Celso

1964 Dialética do desenvolvimento. Rio de Janeiro, Editora Fundo de Cultura.

HEREDIA, Beatriz María Alasia de

1986 As transformações sociais na plantation canavieira: O caso do sul de Alagoas. Rio de Janeiro, tese, Universidade Federal do Rio de Janeiro.

JOHNSON, Allen W.

1971 Sharecroppers of the Sertão: Economics and Dependence on a Brazilian Plantation. Stanford, California, Stanford University Press.

MARQUES, Ana Claudia

2002 Intrigas e questões: Vingança de família e tramas sociais no sertão de Pernambuco. Rio de Janeiro, Relume Dumará. 
MEYER, Doris Rinaldi

1979 A Terra do santo e o mundo dos engenhos: estudo de uma comunidade rural nordestina. Rio de Janeiro, Paz e Terra.

MONTEIRO, Denise Mattos

2007 [2000] Introdução à história do Rio Crande do Norte, $3^{\text {a }}$ Ed. Natal-RN, EDUFRN-Editora da UFRN.

NEIBURG, Federico

2006 "Intimidade e esfera pública: política e cultura no espaço nacional argentino". In: PALMEIRA, Moacir e BARREIRA, Cesar (orgs.).

Política no Brasil: visões de antropólogos. Rio de janeiro, Relume Dumará, Núcleo de Antropologia da Política/UFR], pp. 333-352.

PALMEIRA, Moacir

1977 "Casa e trabalho: nota sobre as relações sociais na plantation tradicional". Contraponto, Rio de Janeiro, Centro de Estudos Noel Nutels, v. II, n. 2: 103-114.

PALMEIRA, Moacir e BARREIRA, Cesar

2006 "Introdução". In PALMEIRA, Moacir e BARREIRA, Cesar (orgs.). Política no Brasil: visões de antropólogos. Rio de janeiro, Relume Dumará, Núcleo de Antropologia da Política/UFR], pp. 9-22.

PEREIRA DE QUEIROZ, Maria Isaura

1976 "O coronelismo numa interpretação sociológica". In PEREIRA DE QUEIROZ, Maria Isaura, O mandonismo local na vida política brasileira e outros ensaios. São Paulo, Editora Alfa-Omega, pp. 161-216.

SECALEN, Martine

1984 “'Avoirsa part': Sibling Relations in Partible Inheritance Brittany". In MEDICK, Hans e SABEAN, David Warren. Interest and Emotion: Essays on the Study of Family and Kinship. Paris e Cambridge, Maison des Sciences de l'Hommee Cambridge University Press, pp. 129-144.

SICAUD, Lygia

1971 A nação dos homens: Uma análise regional de ideologia. Rio de Janeiro, dissertação, Universidade Federal do Rio de Janeiro.

1979 Os clandestinos e os direitos: Estudo sobre trabalhadores da canade-açúcar de Pernambuco. São Paulo, Livraria Duas Cidades. 
ARTICo| Fernanda Figurelli | Historias de familia, historias de propiedad: dinámicas de parentesco en torno a un antiguo latifundio del Nordeste de Brasil

WEBER, Florence

2006 "Lares de cuidado e linhas de sucessão: algumas indicações etnográficas na França, hoje". Revista Mana, Rio de Janeiro, v. 12, n. 2: 479-502.

YANACISAKO, Sylvia Junko

1979 "Family and Household: The Analysis of Domestic

Croups". Annual Review of Anthropology, 8: 161-205 


\section{ABSTRACT}

This article is based on fieldwork in an old large property of cotton and of cattle in Rio Grande do Norte, Brazil. Public archives, former owners and former workers tell a story about the property in which is central the family that owns the land. Thus, when we think about the property, kinship ties of their owners are fundamental. At the same time, the dynamics of these relationships revolves around the land concentration. In this way, rather than a priori delimited entities, we note a mutually constitutive relationship between family and property, which questions the boundaries between "public sphere" and "private sphere". The article proposes the family as a continuous process of production. Also it shows the specific forms that this process take, in which kinship and land concentration are indissoluble.

\section{KEYWORDS}

Family, Property, Public-Private, Kinship Dynamic, Northeast Brazil.

Recebido em 25 de março de 2016. Aceito em 8 de dezembro de 2016. 